
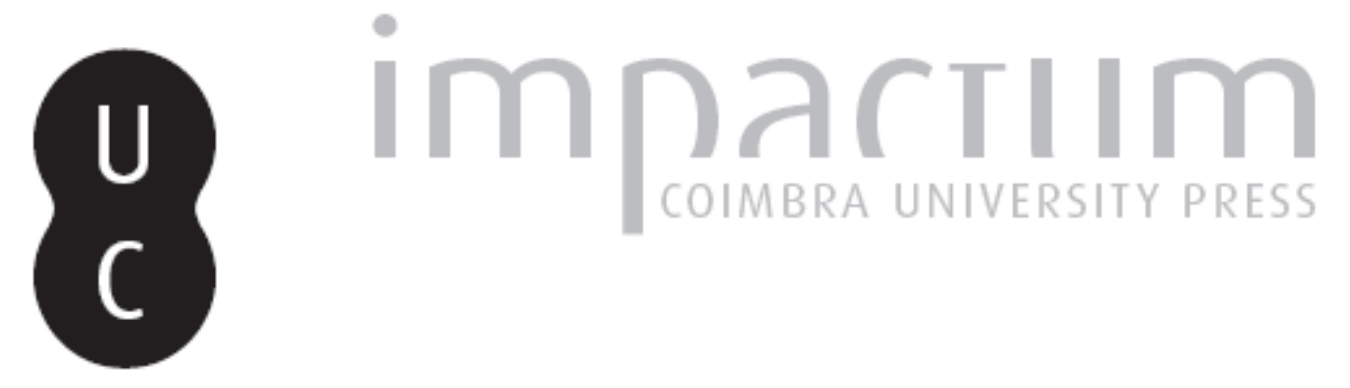

Coisas de princesas: casamentos, dotes e enxovais na família real portuguesa (14801580)
Autor(es):
Sá, Isabel dos Guimarães

Publicado por: Centro de História da Sociedade e da Cultura

URL persistente:

URI:http://hdl.handle.net/10316.2/39514

DOI:

DOI:http://dx.doi.org/10.14195/1645-2259_10-1_4

Accessed : $\quad$ 26-Apr-2023 10:26:12

A navegação consulta e descarregamento dos títulos inseridos nas Bibliotecas Digitais UC Digitalis, UC Pombalina e UC Impactum, pressupõem a aceitação plena e sem reservas dos Termos e Condições de Uso destas Bibliotecas Digitais, disponíveis em https://digitalis.uc.pt/pt-pt/termos.

Conforme exposto nos referidos Termos e Condições de Uso, o descarregamento de títulos de acesso restrito requer uma licença válida de autorização devendo o utilizador aceder ao(s) documento(s) a partir de um endereço de IP da instituição detentora da supramencionada licença.

Ao utilizador é apenas permitido o descarregamento para uso pessoal, pelo que o emprego do(s) título(s) descarregado(s) para outro fim, designadamente comercial, carece de autorização do respetivo autor ou editor da obra.

Na medida em que todas as obras da UC Digitalis se encontram protegidas pelo Código do Direito de Autor e Direitos Conexos e demais legislação aplicável, toda a cópia, parcial ou total, deste documento, nos casos em que é legalmente admitida, deverá conter ou fazer-se acompanhar por este aviso.

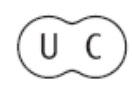




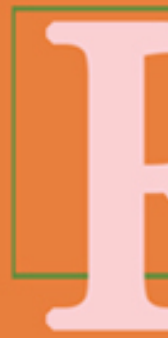

\section{evista de História}

da Sociedade e da

Cultura

\section{Tomo I}

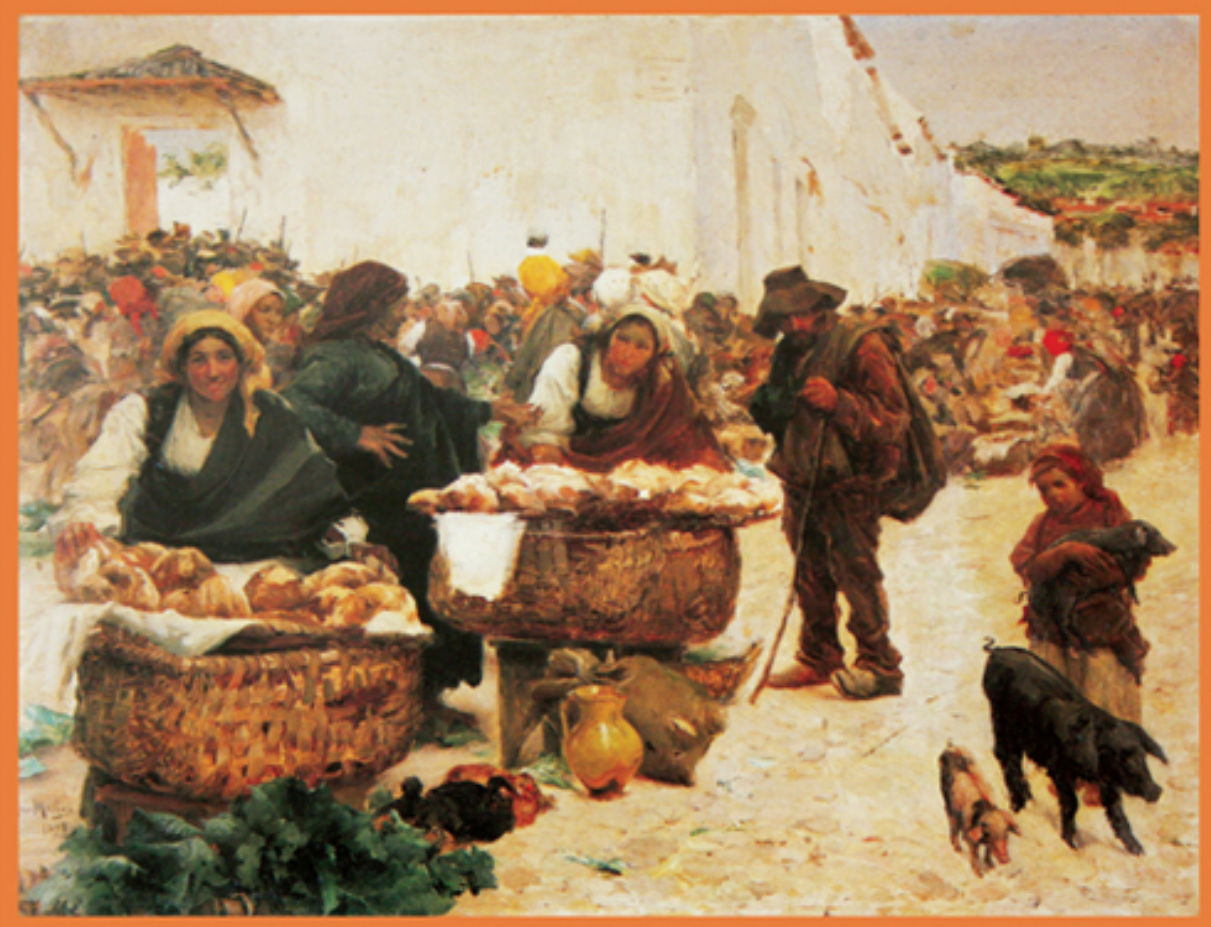

Centro de História da Sociedade e da Cultura Universidade de Coimbra

Coimbra 


\title{
Coisas de princesas: casamentos, dotes e enxovais na família real portuguesa $(1480-1580)^{*}$
}

\author{
Isabel dos Guimarães Sá \\ Departamento de História do Instituto de Ciências Sociais da Universidade do Minho. \\ Investigadora associada do Instituto de Ciências Sociais da Universidade de Lisboa \\ isabeldgsa@mail.telepac.pt \\ Texto recebido em/ Text submitted on: 15/02/2010 \\ Texto aprovado em/ Text approved on: 25/03/2010
}

\section{Resumo/Abstract:}

Num período marcado pela transição da Idade Média para o período moderno, analisam-se as transferências de riqueza operadas pelos casamentos de princesas da casa real portuguesa, no sentido de compreender as respectivas escalas e composições, tentando precisar o valor dos enxovais no conjunto dos dotes. Num primeiro momento, constata-se que, verificando-se uma troca frequente de noivas entre as coroas espanhola e portuguesa, os dotes pagos por esta última são comparativamente bastante mais elevados. Em seguida, estudam-se os enxovais propriamente ditos, no que toca aos hábitos de consumo que evidenciam, e à forma como seriam usados nos aposentos de princesas e rainhas. O estudo evidenciou uma burocratização crescente da gestão dos enxovais, a introdução de objectos próprios do período moderno, muitos deles orientais, bem como o aumento das preocupações com os cuidados do corpo. Todavia, sugere-se a ausência de indicadores de uma emergência do privado na vida destas princesas e rainhas, que, pelo contrário, foram objecto de crescente vigilância.

This article analyses the transfers of wealth through mariage of the princesses of the Portuguese royal house, during the transition period from the Middle Ages to the Modern Period, hereby seeking to understand the scale and composition of such wealth and attempting to estimate the value of the trousseau in the dowry. At first sight, in the frequent exchanges of brides between the Spanish and Portuguese crowns, it is noted that dowries paid by the latter were considerably higher, the paper also focuses the trousseaus, which shed light on consumption habits and the use of objects in the queens' and princesses' private chambers. The survey outlines the increased bureaucracy involved in the management of the trousseaus, the introduction of objects typical of the Early Modern Period, many of which from the East, as well as growing concerns with body care. However, the author outlines the absence of indicators of arising privacy in the lives of these princesses and queens, who were on the contrary subjected to increasing supervision.

Palavras chave/Keywords:

Dotes; Enxovais; Consumo; Cultura Material; Interiores domésticos.

Dowries; Trousseaus; Consumption; Material Culture; Domestic life.

* Este artigo integra o projecto Portas Adentro: Modos de Habitar do século XVI a XVIII em Portugal, financiado pela Fundação Ciência e Tecnologia, com a referência PTDC/ /HAH/71309/2006. Agradecem-se as questões colocadas pelo público aquando da apresentação de uma primeira versão deste trabalho no Seminário de História do Instituto de Ciências Sociais da Universidade de Lisboa em 23 de Feveiro de 2007. 


\section{Introdução}

Este trabalho pretende constituir uma tentativa de abordagem dos casamentos das princesas da casa real portuguesa sob o ponto de vista patrimonial. Os aspectos de política internacional de que estes casamentos eram expressão terão aqui menos atenção. Como se sabe, estas uniões tinham objectivos político-militares imediatos, como firmar a paz depois de uma guerra; por vezes incorporavam indemnizações no seguimento destas últimas ou pagamentos para regular questões entre casas reinantes; podiam significar estratégias a curto ou médio prazo no sentido da incorporação de novos reinos nas monarquias compósitas da época. O objectivo principal, no entanto, é o de tentar compreender estes casamentos do ponto de vista contratual, as démarches que envolviam, e sobretudo o de analisar as transferências de bens que implicavam. Aborda-se aqui o lado material da vida social e política das sociedades portuguesas da alta Idade Moderna, na perspectiva da relação entre as pessoas e as coisas, e de que forma os consumos reflectem escolhas e formas de posicionamento social e político dos indivíduos.

O interesse por este tema decorre de uma investigação que desenvolvo sobre o século XVI em Portugal, ou melhor, sobre o período compreendido entre 1480 e 1580, que no meu entender configura a transição da época medieval para a moderna. A última destas datas tem um peso acrescido por significar o desenlace das alianças matrimoniais praticadas ao longo deste século, através da incorporação da coroa portuguesa na monarquia espanhola por via de sucessão dinástica legítima.

Os enxovais das princesas recebem atenção preferencial neste artigo, no sentido de os posicionar no conjunto da riqueza transferida pelas infantas através do casamento. Para o conseguir, houve que decompor o casamento nos seus passos processuais, desde a negociação até à consumação, e saber quais os tipos de bens transferidos. Como se sabe, as princesas levavam para o casamento um dote, um enxoval, que como veremos, não incorporava necessariamente o primeiro, e eram supostas suportar os gastos das suas pessoas e casas através de uma anuidade, o assentamento. Por outro lado, as festividades a que os casamentos davam azo, por vezes durante dias e até semanas, representavam por si só despesas avultadas, para além das 
viagens das princesas e suas comitivas ao encontro dos seus maridos. A primeira etapa do trabalho será compreender de que modo o enxoval se articula com os restantes bens movimentados por estes casamentos. Num breve momento, analisar-se-ão as cerimónias e rituais a que um casamento dá lugar. Finalmente, estudam-se alguns enxovais à luz da sua composição e do significado e valor que os objectos que os formam constituem. Para finalizar, proceder-se-á a uma reflexão sobre a forma como o advento do período moderno se reflecte na sua composição . Dois indicadores de mudança serão observados. O primeiro consiste em verificar se existe uma tendência crescente para burocratizar os processos de transferência, isto é, os procedimentos administrativos em torno da inventariação do enxoval, e os próprios protocolos de utilização dos objectos que o formam. O segundo consta em apurar em que medida os objectos que se divulgam a partir do período moderno estão presentes nesses enxovais, tomando como exemplo de mudança alguns objectos considerados paradigmáticos dos novos hábitos de consumo do período, pelo seu uso se ter generalizado a partir de então: espelhos de cristal, leques, guardanapos e garfos de uso individual. A presença destes objectos indicia uma nova relação com o corpo, cada vez mais consciente da importância da saúde e da apresentação externa, para além de constituírem (em particular os dois últimos exemplos, os guardanapos e os garfos) indícios do processo de privatização, tal como foi enunciado por Philippe Ariès. Inspirando-se em Norbert Elias, este autor definiu este processo evolutivo como a crescente importância da vida privada dos indivíduos, através da segregação entre espaços / públicos e privados e de um uso crescente da etiqueta de corte ${ }^{1}$.

Entendo cada um dos casamentos abordados como um caso específico em si mesmo: a ele corresponde uma configuração própria que pode eventualmente pôr em causa uma análise agrupada destes matrimónios, que é justamente o que pretendo fazer. Como veremos, a documentação disponível é desigual: os contratos de casamento encontram-se praticamente todos publicados, enquanto que os inventários de jóias e enxovais foram

1 ARIÈS, Philippe - Para uma História da Vida Privada in ARIÈS, Philippe e DUBY, Georges - História da Vida Privada. vol. 3, Porto: Afrontamento, 1990, p. 7-19. ELIAS, Norbert - O Processo Civilizacional. 2 vols., Lisboa: Dom Quixote, 1989. 
impressos apenas em relação a dois casos, sem que se encontrem versões manuscritas para os restantes.

O critério que presidiu à selecção efectuada foi o casamento com reis ou herdeiros directos do trono. Dois casos apenas constituem excepções, o de Beatriz, filha de D. Manuel, que casou com o duque de Sabóia, e o de Maria, filha do infante Duarte e de Isabel, duquesa de Bragança, que casou com o herdeiro do ducado de Parma.

\section{I . Preparar os casamentos: os negócios}

É bem conhecida a tendência da coroa portuguesa para casar os seus príncipes e princesas com os seus homólogos da coroa espanhola. Só no período que ora nos ocupa, a lista seria extensa: D. João II casou o seu único filho Afonso com Isabel, a filha mais velha dos Reis Católicos, que seria por sua vez a primeira mulher do seu sucessor, D. Manuel I. Morta esta, casou D. Manuel com uma sua irmã, Maria. A filha mais velha de Manuel I casaria com Carlos V, enquanto o rei casaria em terceiras núpcias com a irmã mais velha deste último, Leonor (1498-1558). D. João III casou com outra irmã de Carlos V, Catarina, enquanto os seus filhos adolescentes João e Maria casariam por sua vez com filhos da tia Isabel e do tio Carlos: Maria casou com o príncipe herdeiro Filipe, e João com Joana de Áustria. Houve apenas uma excepção a este padrão, o casamento de Beatriz, filha de D. Manuel I, com o duque de Sabóia. De notar que D. Manuel teve o cuidado de conceder uma filha segunda, reservando a mais velha, Isabel, para uma união mais vantajosa que teria lugar anos depois. Existe de facto uma primogenitura do género feminino, isto é, a primeira filha era reservada para o casamento a que se atribuía maior importância. De resto, por exemplo, já o príncipe D. Afonso teria recebido um dote mais substancial se tivesse casado com Joana, irmã mais nova de Isabel, filha primogénita de Fernando e Isabel, como a certa altura chegou a estar combinado entre os dois intervenientes, de forma a compensar o seu afastamento na linha sucessória ${ }^{2}$. O nosso

2 RESENDE, Garcia de - Crónica de D. João II e Miscelânea. Lisboa: Imprensa Nacional, 1973, p. 47. 
último caso, o casamento de Maria de Portugal com o príncipe de Parma, que poderia parecer à primeira vista um casamento no exterior das casas reinantes ibéricas, era na verdade o casamento de Maria com um neto por via ilegítima de Carlos $\mathrm{V}$ e foi agenciado por Filipe $\mathrm{II}^{3}$. O noivo era filho de Margarida de Áustria, filha ilegítima de Carlos V. A noiva, D. Maria (15381577) era filha do infante D. Duarte, irmão de D. João III, e da duquesa de Bragança, Isabel. O casamento teve lugar na corte, em Lisboa, na presença de Henrique, o cardeal regente, da rainha viúva Catarina e do jovem D. Sebastião ${ }^{4}$.

Será necessário, no entanto, explicar esta obsessão dinástica à luz dos seus momentos fundacionais. De facto, esta vaga de casamentos ibéricos decorre da derrota de Afonso V em Toro, do fim das terçarias de Moura e tem início com o casamento do príncipe D. Afonso unigénito de D. João II e de D. Leonor, com Isabel, primogénita dos Reis Católicos ${ }^{5}$. Foi também poucos anos depois que estes últimos contrataram um casamento cruzado, ao casar o seu herdeiro João com a princesa Margarida de Borgonha, e o irmão desta, Filipe o Belo, com a filha Joana, irmã de João, mais tarde conhecida por Joana a Louca. Para Bartolomé Bennassar, foi o primeiro casamento que inaugura este sistema cruzado nas políticas matrimoniais europeias, que se prolonga até ao século XVIII; no entanto, sabemos que era prática frequente na Idade Média $^{6}$. Tal não impede, no entanto, que os historiadores do período moderno tenham descurado analisar algumas destas alianças matrimoniais à luz de uma troca simultânea, o que as transforma em uniões cruzadas de primos direitos. Com efeito, Carlos V trocou sua irmã Catarina pela irmã do seu primo D. João III, a futura imperatriz Isabel. Cerca de duas décadas mais tarde, uma nova aliança cruzada teria lugar: os filhos

3 Biblioteca da Ajuda (doravante BA), Cód. Ms. 51-VIII-2, fls. 1-24 [Bruxelas, 1566.03.07].

4 BERTINI, Giuseppe - The Marriage of Alessandro Farnese and D. Maria of Portugal in LOWE, K.J.P. - Cultural Links between Portugal and Italy in the Renaisance, Oxford: Oxford University Press, 2000, p. 45-49.

5 Muita coisa se escreveu sobre esta guerra, e a bibliografia seria extensa. Vejam-se, por todos: FONSECA, Luís Adão da - D. João II. Lisboa: Círculo de Leitores, 2005 e SUÁREZ FERNÁNDEZ, Luís - Isabel I, Reina (1451-1504). 4ª ed., Barcelona: Ariel, 2006.

6 BENNASSAR, Bartolomé - Le Lit, le Pouvoir et la Mort. Reines et Princesses d'europé de la Renaissance aux Lumières. Paris: Éditions de Fallois, 2006, p. 53. 
de ambos casariam entre si. A princesa Maria com o primogénito e herdeiro de Carlos V, Filipe, e o herdeiro de D. João III, o príncipe João, com a prima Joana, irmã de Filipe. O casamento cruzado foi de resto assumido através de um contrato nupcial conjunto, celebrado no paço dos Estaus em $1542^{7}$. Na verdade, estas uniões cruzadas consolidavam acordos políticos, ao mesmo tempo que prometiam uma relação de reciprocidade, por vezes mais fictícia do que real. As cláusulas (ou capitulações, como aparecem designadas nos contratos) eram recorrentes, e aparentemente iguais. A variação significativa ocorria nas somas transaccionadas, nem sempre equivalentes. No caso português, estes contratos cruzados, correspondentes a casamentos entre as duas casas reinantes, foram todos celebrados entre o imperador Carlos V e D. João III.

A coroa portuguesa viria a ficar fragilizada pela atenção que concentrou nas alianças com Espanha, uma vez que não diversificou as suas alianças com parceiros de várias casas reinantes, ao contrário dos Habsburgos. Enquanto os rebentos da família real portuguesa casavam apenas com membros do ramo Habsburgo de Espanha, estes por sua vez alargaram-nas a toda a Europa. Foi este um ponto fraco, de resto, da política portuguesa, e com toda a probabilidade o resultado de uma estratégia mais ou menos consciente da coroa espanhola para a manter sob controlo.

A vertente política destes casamentos tem sido também profusamente estudada: sabe-se que tinham o condão sobretudo de rematar o fim dos conflitos entre os soberanos. A fusão de duas famílias rivais através do casamento tinha a vantagem (a par de muitas desvantagens) de a transformar numa só família, consolidando solidariedades dinásticas que, como se sabe, para estas pessoas, precediam sobre considerações "nacionais". Eram sobretudo uniões de sangue que selavam pactos de não agressão, ao incorporarem inimigos passados ou potenciais futuros adversários na própria família. Os contratos dizem-no de forma explícita: visavam o sossego dos reinos e possessões dos dois intervenientes, e um deles, o de 1542, falava ainda de um compromisso de lutar contra os inimigos comuns. Do ponto de vista dinástico, estes casamentos constituíam uma roleta russa: o primeiro

7 GAVETAS (As) da Torre do Tombo, 12 vols., Lisboa: Centro de Estudos Históricos Ultramarinos, 1960-1977. Neste caso, vol. V, p. 538-557. 
trono a ficar sem herdeiro directo seria na realidade absorvido pelo outro, e foi o que aconteceu com Portugal no take over de Filipe II, que era, segundo a lógica dinástica, um dos herdeiros legítimos da coroa portuguesa. Esse jogo, eminentemente aleatório, mas também onde não faltavam as jogadas ardilosas dos seus intervenientes, tinha de resto dado a Carlos V a possibilidade de herdar a Borgonha e a Flandres em 1506, a Espanha e as Índias em 1516, e os territórios dos Habsburgos em 1519, ano em que também conseguiu ser eleito imperador do Sacro-Império, sucedendo a seu avô paterno, Maximiliano (1459-1519).

Também não passou despercebida a importância de que estes casamentos se revestiam do ponto de vista económico. Historiadores como Fernández Alvarez sublinharam a estratégia de Carlos V de angariar dinheiro para as suas campanhas militares através dos casamentos com Portugal, incluindo o seu próprio enlace com Isabel, filha mais velha de D. Manuel I ${ }^{8}$.

Os casamentos nas casas reais eram portanto momentos fundamentais do ponto de vista político e económico, uma vez que condicionavam a reprodução biológica do casal a alianças cruciais para as unidades políticas intervenientes. No entanto, pela natureza dos interesses envolvidos, estes casamentos podiam estar votados ao fracasso. As expectativas neles depositadas estavam, em última análise, dependentes do seu sucesso reprodutivo. Em todo o caso as mulheres constituíam bens de troca fundamental; Lisa Jardine afirmou que eram importantes "peças de propriedade dinástica" . Podemos chamar-lhes "bens de exportação", na medida em que constituíram peças cruciais nos jogos dinásticos europeus, sempre virilocais, implicando para as princesas um abandono da corte natal e a residência no estrangeiro.

Nestes casamentos há que considerar em primeiro lugar o papel dos negociadores, inerente aos detentores do poder paternal segundo a lógica vigente na época. No caso dos menores, o pai, ou, na falta deste, um irmão ou a mãe. No caso dos príncipes sui juris, essa competência cabia ao próprio: foi o caso de D. João III, sem pai ou mãe vivos quando subiu ao trono ainda solteiro em 1521. Cabe salientar que, não obstante o facto de a família

\footnotetext{
8 FERNÁNDEZ ÁLVAREZ, Manuel - Carlos V, El César y el Hombre. Madrid: Espasa Calpe, 1999, p. 327-328.

9 JARDINE, Lisa - Worldly Goods. A New History of the Renaissance. New York: Norton, 1996, p. 408-410.
} 
angariar estes casamentos, havia uma ressalva para o consentimento dos prospectivos noivos. Isto é, no caso das princesas, algumas recusavam as propostas de casamento, e essa decisão impedia a sua realização. Portanto, eram casamentos arranjados, mas não forçados (terão provavelmente ocorrido excepções, mas a lógica do consentimento deveria prevalecer). Embora a tendência fosse no sentido de se exercerem pressões sobre os potenciais noivos, conhecemos casos de recusa em casar. De todo, como aconteceu com a princesa D. Joana (1452-1490), irmã de D. João II, ou com certos pretendentes, como foi o caso de Isabel de Castela, por exemplo, que rejeitou várias hipóteses de casamento até casar com Fernando o Católico, que fez a viagem de Aragão para Castela disfarçado de mercador (exactamente porque era o último casamento que interessava à família da noiva). Naquele contexto, foi um dos actos fundacionais mais importantes da hegemonia de Isabel, que preparou o seu futuro como membro de um casal em que ambos tinham o estatuto de monarcas reinantes, conforme constaria das condições impostas pela própria noiva ${ }^{10}$.

Os dotes das princesas eram compostos por uma soma paga ao marido num prazo que contava a partir da consumação do casamento, após uma breve cerimónia matrimonial na igreja. Isto é, estes casamentos desenvolviam-se em várias fases: no momento do contrato, existia um juramento, que funcionava como um casamento por palavras de futuro; em seguida, aguardava-se a chegada da dispensa papal (quando os noivos eram parentes chegados) para celebrar um casamento por procuração, que correspondia a uma casamento por palavras de presente. Só em seguida as noivas viajavam para o país dos noivos, e se procedia à consumação do casamento após uma cerimónia religiosa na igreja. O facto mais importante a assinalar é que a consumação assinalava a validação do acto matrimonial, passível de ser dado por nulo até esse momento.

Era no dote que se concentrava a atenção dos intervenientes, porque, em caso de haver descendência do casal, o marido não teria de o restituir. Desse ponto de vista, o dote constituía uma entrada de capital significativa

${ }^{10}$ LISS, Peggy K. - Isabel the Queen. Life and Times, revised edition. Philadelphia: University of Pennsylvania Press, 2004, p. 51-68. 
para o noivo. O exemplo mais notório do uso sistemático dos dotes foi o de Carlos V que os utilizou para financiar as suas numerosas campanhas militares. Neste contexto, os contratos são explícitos: as jóias e coisas de prata e ouro faziam parte integrante do dote, mas eram comuns ao casal, o que significava que o marido podia dispor deles. Formavam um grupo distinto dos "vestidos e atavios de pessoa, câmara e casa", que eram propriedade exclusiva da noiva. Daí que, como veremos, há no dote de D. Maria (1527-1545) - noiva de Filipe - uma secção que lida apenas com o conjunto das jóias, prata, pérolas e outros valores, que no contrato não podiam exceder um décimo do valor do dote, sendo detalhadamente inventariados. O que faz com que se compreenda, por exemplo, porque é que a princesa de Castela levava, entre tantas outras coisas, qualquer coisa como cerca de 4400 pérolas de vários tamanhos e qualidades, entre muitas outras preciosidades ${ }^{11}$. Evidentemente, tratava-se de valores monetarizáveis e não apenas ornamentos de sua pessoa, que não se podem confundir com o enxoval propriamente dito. Constituía, é claro, uma distinção ambígua, porquanto não era dito em nenhum lado que alguns vestidos e atavios não usassem metais e pedras preciosas. Por outro lado, muitos dos objectos de ouro e prata eram de uso de casa ou corpo, como os bacios de serviço, a baixela, ou os livros de devoção ornamentados com ouro e pedras preciosas. No caso de D. Maria esses bens estavam a cargo de André Soares, responsável pela entrega do dote, a quem foi dado um regimento expresso, com ordens para as coisas de que a princesa se quisesse servir serem dadas "por empréstimo" à sua camareira-mor, que assinava um papel dando conhecimento de que as tinha levado e comprometendo-se a devolvê-las ${ }^{12}$. O que leva a concluir que as jóias não tinham a mesma natureza dos enxovais. Em todos os contratos, sem excepção, "os atavios de casa e pessoa", expressão que os designa -

${ }^{11}$ SOUSA, D. António Caetano de - Provas da História Genealógica da Casa Real Portuguesa, ed. revista por M. Lopes de Almeida e César Pegado. Coimbra: Atlântida, 1947-1950, vol. III, parte I, p. 211-245.

${ }^{12}$ Relações de Pero de Alcáçova Carneiro Conde da Idanha do tempo em que ele e seu pai, António Carneiro, serviram de secretários (1515 a 1568), ed. de Ernesto Campos de Andrada. Lisboa: Imprensa Nacional de Lisboa, 1937, pp. 292-298. Annemarie Jordan observou a mesma organização burocrática na colecção da mãe da princesa, D. Catarina de Áustria (The Development of Catherine of Austria's Collection in the Queen's Household: its Character and Cost. Tese de doutoramento, Providence: Brown University, 1994, p. 111). 
sem as jóias - não eram restituíveis à família de origem, nem propriedade do casal, mas bens exclusivos da noiva, o que implicava que esta pudesse dispor deles com inteira liberdade.

O quadro 1 pretende sistematizar as trocas de capitais envolvidas por estes contratos

Quadro 1 - Dotes, enxovais e assentamentos

\begin{tabular}{|c|c|c|c|c|c|c|c|}
\hline $\begin{array}{c}\text { Data } \\
\text { contrato }\end{array}$ & Princesa & $\begin{array}{c}\text { Dobra } \\
\text { espanhola } \\
\text { (db) }\end{array}$ & $\begin{array}{l}\text { Contos } \\
\text { de réis }\end{array}$ & \begin{tabular}{|l|} 
Rendas \\
"públicas" \\
(em contos)
\end{tabular} & $\begin{array}{l}\text { Jóias \& } \\
\text { enxoval }\end{array}$ & $\%$ & $\begin{array}{c}\text { Assentamento } \\
\text { (contos/ano) }\end{array}$ \\
\hline 1473 & Leonor & & 3,9 & 43 (1477) & Incluídos & ? & 1,5 \\
\hline 1496 & Isabel & 70.333 & & & $\begin{array}{c}\text { Não } \\
\text { incluídos }\end{array}$ & ? & 3,6 \\
\hline 1500 & Maria & 200.000 & & & $\begin{array}{l}10.000 \mathrm{db} \\
\text { (só jóias). }\end{array}$ & $5+?$ & 4,5 mrv \\
\hline 1518 & Leonor & 200.000 & & & $\begin{array}{l}10.000 \mathrm{db} \\
\text { (só jóias) }\end{array}$ & $5+?$ & $\begin{array}{c}2 \mathrm{mrv}+ \\
15.000 \mathrm{db}\end{array}$ \\
\hline 1521 & Beatriz & - & 60 & 114 (1518-) & 20 & 33,3 & $\begin{array}{c}20.000 \\
\text { ducados }\end{array}$ \\
\hline 1524 & Catarina & 200.000 & 77,87 & & - & & $4+2 \mathrm{mrv}$ \\
\hline 1525 & Isabel & 900.000 & 350,4 & & - & & $7,5 \mathrm{mrv}$ \\
\hline 1543 & Maria & & 160 & $155(1534)$ & - & $10+?$ & $8,5-12,8^{*}$ \\
\hline 1543 & Joana & & 80 & & - & & $\begin{array}{c}4,3-7,4^{*}+\mathbf{2 , 1}{ }^{*} \\
(\text { Carlos V) }\end{array}$ \\
\hline 1565 & \begin{tabular}{|c|} 
Maria \\
Portugal
\end{tabular} & & \begin{tabular}{|c|}
70 mil \\
ducados
\end{tabular} & $\begin{array}{l}303,5 \\
(1557)\end{array}$ & $\begin{array}{c}16+4 \text { mil } \\
\text { ducados }\end{array}$ & 28,6 & \\
\hline
\end{tabular}

Nota: equivalências da moeda não disponíveis para o maravedi ( $\mathrm{mrv}$ - em contos de maravedis no quadro), dobra espanhola $(\mathrm{db})$ e ducados. Os asteriscos $(*)$ correspondem às somas estipuladas para quando passassem de princesas a rainhas. A negrito, encontram-se assinalados os assentamentos pagos pela família da noiva e não do noivo.

Fontes: Contratos matrimoniais: 1473: Sousa, Provas, t. II, I parte, p. 224-230; 1496: Gavetas, vol. VII, p. 131-140; 1500: Gavetas, vol. VII, p. 487-495; 1518: Gavetas, vol. VI, p. 489-501; 1521: Sousa, Provas, t. II, II parte, p. 18-26; 1524: Gavetas, vol. VII, p. 433448; 1525: Gavetas, vol. VII, p. 49-55; 1543: Gavetas, vol. V: 538-557; 1565: Biblioteca da Ajuda, Cód. Ms. 51-VIII-2, fls. 1-24. Rendas "públicas" calculadas com base em Godinho (1978), ver nota 15.

As somas astronómicas envolvidas transformavam estes casamentos em assuntos de primeira importância. São de resto conhecidas as clivagens de opinião em torno de alguns destes enlaces, como é o caso das críticas feitas a D. João III por casar a filha Maria com Filipe príncipe das Astúrias e herdeiro do trono de Castela (depois Filipe II, 1527-1598) ${ }^{13}$. Para o povo

${ }^{13}$ BUESCU, Ana Isabel - Catarina de Áustria Infanta de Tordesilhas Rainha de Portugal. Lisboa: Esfera dos Livros, 2007, p. 253-257. 
estes casamentos podiam significar presentes mais ou menos forçados, ou por vezes impostos extraordinários, como foi o caso do casamento do príncipe D. Afonso com Isabel, filha dos Reis Católicos ${ }^{14}$.

Em termos portugueses, basta uma pequena comparação com os orçamentos régios anuais para se perceber a escala dos capitais envolvidos (ver quadro 1). Magalhães Godinho estimou as rendas públicas em 43 contos em 1477, 76,8 em 1506, 114 contos em 1518-19, 155 em 1534 e 303,5 em 1557 , ano da morte de D. João III ${ }^{15}$. As somas astronómicas envolvidas nos dotes representavam portanto transferências de capital consideráveis; não se enganavam aqueles que consideravam estes casamentos ruinosas drenagens de riqueza para o reino vizinho.

Para além do valor absoluto dos dotes pagos pelo rei de Portugal ao rei espanhol, fica também patente a desigualdade entre os dotes pagos pelos dois monarcas. Com efeito, em 1525, o dote da infanta D. Isabel foi 4,5 vezes superior ao que Carlos V concedeu a sua irmã Catarina; vinte anos mais tarde as somas envolvidas nos dotes seriam globalmente bastante inferiores, o que não impediu João III de pagar o dobro pelo dote de Maria do que Carlos V pagava pelo de Joana. Para mais, neste último caso, o pagamento português devia ter lugar em dois anos, enquanto o prazo de Carlos V se estipulava no dobro desse tempo ${ }^{16}$. Não existe no entanto ainda resposta para a questão mais importante, que seria a de saber a razão desta desigualdade. Havia, é certo, o problema das Molucas ainda pendente entre a coroa espanhola e portuguesa: no seguimento da viagem de Fernão de Magalhães, Carlos V reclamava para si a posse das ilhas, e esta questão influiu certamente nos contratos matrimoniais. No entanto, a drenagem de capital para Espanha não acabou: a questão só ficou definitivamente resolvida através do tratado de Saragoça quando D. João III comprou por 350 mil ducados o direito às ilhas em $1529^{17}$.

${ }^{14}$ RESENDE, Garcia de - Crónica de D. João II..., cit., p. 144-145.

${ }^{15}$ GODINHO, Vitorino Magalhães - Finanças Públicas e Estrutura do Estado in Ensaios II. $2^{\text {a }}$ ed., Lisboa: Sá da Costa, 1978, p. 55.

${ }^{16}$ In Gavetas..., cit., vol. VII, p. 38-39.

${ }^{17}$ Sobre a desvantajosa solução encontrada para a coroa portuguesa cf. ALBUQUERQUE, Luís de - Molucas in ALBUQUERQUE, Luís de (coord.) - Dicionário de História dos Descobrimentos Portugueses, vol. II, Lisboa: Caminho, 1994, p. 755-758. 
Ainda, quando se pensa nos encargos financeiros com as casas das princesas/rainhas, há que ter em conta que as transferências de bens vão muito além do núcleo constituído pelo dote, jóias e enxoval. Como se tratava de casamentos virilocais, competia ao noivo assegurar um conjunto de cidades, vilas e terras que pudessem sustentar a casa da rainha através de uma renda anual estável. Ou seja, o dote podia ser uma forma de garantir ao marido liquidez imediata; mas não era o que sustentava a esposa. Esse papel cabia ao assentamento anual, normalmente pago pelo marido, e ao conjunto de terras cujas rendas suportavam os gastos das casas das princesas e rainhas, sendo que estava previsto um aumento substancial do rendimento quando os maridos subiam ao trono.

Por vezes existiam dificuldades em encontrar meios de sustento anual para as rainhas, como no caso em que a viúva do rei anterior ainda vivia. Foi o que aconteceu com rainha D. Leonor, viúva de D. João II: sobreviveu ao marido trinta anos, às rainhas suas cunhadas Isabel e Maria, e finalmente ao próprio rei seu irmão, falecido em 1521 . Na prática, sobreviveu a três rainhas consortes, uma vez que a terceira, Leonor, se retirou para Castela depois da morte de D. Manuel I. Quando D. João III casou com Catarina ainda estava viva, tendo vindo a falecer precisamente no final desse ano. Qualquer um destes quatro contratos tem uma cláusula que estipula que assim que D. Leonor morresse as terras que detinha voltariam à posse das rainhas em exercício ${ }^{18}$. Enquanto tal não acontecia, os assentamentos destas rainhas foram pagos pelas famílias de origem. D. Leonor morreu escassos meses depois de Catarina ter entrado no reino, pelo que na prática houve quatro contratos de casamento de rainhas efectuados durante a sua viuvez. Quando D. Manuel casou pela segunda vez, com a infanta D. Maria de Castela, provavelmente para compensar a nova rainha, ofereceu-lhe um magnífico presente em jóias e objectos preciosos, e doou-lhe Viseu e Torres Vedras ${ }^{19}$. Por outro lado, mencionámos já as dificuldades de liquidez da coroa

${ }^{18}$ Note-se que a coroa portuguesa era ainda responsável pela manutenção do trem de vida da Excelente Senhora, D. Joana de Castela, que vivia desde 1504 no paço das Alcáçovas; era considerada rainha por muitos (fora a rival de Isabel a Católica na guerra de sucessão (1576-79) e mulher de Afonso V de Portugal.

19 TORRE, Antonio de la e Suárez Fernández, Luis (eds) - Documentos Referentes a las Relaciones com Portugal durante el Reinado de los Reyes Católicos. 3 vols., Valhadolid: CSIC, 1958-1963. Neste caso, vol. III, p. 70-76. Ver também BRAGA, Paulo Drummond 
castelhana para quem provavelmente era mais fácil pagar uma anuidade do que um dote, para o qual seria necessário reunir uma soma avultada. As arras, em contrapartida, constituíam um fundo de segurança: eram pagas à esposa unicamente no caso de o matrimónio se dissolver, com ou sem filhos, destinando-se a suportar os encargos de um eventual repúdio ou viuvez, e por essa razão não foram aqui consideradas ${ }^{20}$.

\section{Concretizar: as bodas}

\section{Partidas e chegadas: as trocas de noivas}

O momento ritual da troca era concretizado quando a noiva chegava à raia e era entregue à família do marido. Estes casamentos, por terem sido efectuados com herdeiros do trono, eram forçosamente virilocais, e competia aos contraentes financiar as viagens dos filhos até à fronteira. $\mathrm{O}$ ponto de encontro das comitivas respectivas era combinado com antecedência e, nos casos dos casamentos cruzados, a troca de noivas ocorria em simultâneo sempre que possível.

Os casamentos das filhas eram portanto momentos de despedida. Garcia de Resende contou com algum detalhe a forma afectuosa como Beatriz se despediu dos irmãos e do pai. Os primeiros vieram a bordo do barco onde a princesa estava instalada todas as noites antes da partida; D. Manuel veio na última delas e demorou-se a conversar com a filha a sós. Na biblioteca de Turim existem as instruções que deu à filha para a guiarem no seu novo estado matrimonial ${ }^{21}$. Trata-se obviamente de um documento formal, mas que, talvez por ter sido estimado pela princesa, que não o destruiu, sobreviveu até aos nossos dias. Devia Beatriz obedecer a Deus e ao marido, por esta ordem; administrar da melhor forma as suas terras; evitar gastos supérfluos;

- Da gestão de um património. Análise da Chancelaria da Rainha D. Maria, mulher de D. Manuel I. Beira Alta. LI (1992) 74.

${ }^{20}$ RODRIGUES, Ana Maria S. A., For the Honor of Lineage and Body: the Dowers and Dowries of Some Late Medieval Queens of Portugal. e-Journal of Portuguese History, 5 (2007).

${ }^{21}$ BA, Cód. Ms. 51-VIII-1, fls. 1-7. Trata-se de uma fotografia do original conservado em Turim, muito apagada, transcrito em FERNANDES TOMÁS - Cartas Bibliographicas. $2^{\mathrm{a}}$ série, Coimbra: Imprensa da Universidade, 1877, p. 18-23. 
guardar parte da sua renda para esmolas; favorecer os homens e mulheres honrados e de bons costumes da sua corte. O texto terminava exortando Beatriz a seguir os bons exemplos da avó materna e paterna, que a princesa, note-se, não podia ter conhecido senão através da memória que delas tinha ficado na corte de seus pais. A avó materna, Isabel a Católica, morreu em 1504 e a paterna, D. Brites duquesa de Beja, - de quem a infanta tomou o nome -, morreu em 1506. Trata-se portanto de um apelo à memória familiar e dinástica por parte de D. Manuel. Na ausência de ambas, o membro feminino mais velho da família com quem Beatriz se podia ainda encontrar era a rainha velha, viúva de D. João II, ou seja a tia Leonor, irmã de seu pai, como de facto aconteceu. Garcia de Resende narra que Beatriz foi despedir-se da tia Leonor ao seu paço de S. Éloi antes de partir para Sabóia, juntamente com o rei e a rainha, e os infantes seus irmãos, exibindo-se ricamente ataviados no trajecto pelas ruas de Lisboa $^{22}$.

Poucas princesas voltaram aos lugares da infância depois do casamento; fizeram-no em caso de viuvez sobretudo. Algumas, como Leonor (1498-1558), terceira mulher de Manuel I, ou Joana de Áustria (1535-1573), tiveram de deixar filhos de poucos meses quando regressaram aos seus países de origem. A primeira deixou a infanta D. Maria (1521-1577), com quem se encontraria apenas uma única vez, semanas antes de morrer; a segunda deixou D. Sebastião entregue aos cuidados da avó paterna, a rainha viúva D. Catarina.

As recepções de princesas eram momentos significativos, para os quais o rei destacava os fidalgos de linhagem mais elevada para tomarem parte no processo de entrega, mas não eram ainda o encontro dos noivos. A comitiva de acolhimento tinha justamente o papel de acompanhar a noiva até ao lugar onde se encontraria com o marido. Um relato dá-nos conta de D. João III escondido e incógnito, a tentar ver a noiva antes de se encontrar com ela dias depois ${ }^{23}$.

Seguiam-se-lhe invariavelmente dias de festa, e o momento alto do casamento era, como referimos, a sua consumação, que concentrava as atenções de todos. Embora as fontes não o mencionem para os casamentos

${ }^{22}$ RESENDE, Garcia de, Crónica de D. João II..., cit., p. 325.

${ }^{23}$ BA, cód. 51-VI-40, fls. 41-54. 
envolvendo a casa real portuguesa, ainda não muitos anos antes, no casamento de Isabel a Católica com Fernando se seguira o costume de verificar a virgindade da noiva expondo ao público os lençóis nupciais, na manhã seguinte à primeira noite ${ }^{24}$.

\section{Dias de festa}

As festas de casamento duravam semanas e tinham o carácter de um potlatch tal como este foi definido por Marcel Mauss, no seu célebre Ensaio sobre a dádiva. Isto é, caracterizavam-se pela oferta conspícua de comida e bebida, que se estendia por vezes a não consumíveis.

Por exemplo, vejamos o caso da infanta D. Leonor (filha de D. Duarte e irmã de D. Afonso V) que casou com Frederico III, imperador da Alemanha e pai de Maximiliano I, em 1452. Em Lisboa, antes da princesa viajar para Siena, onde viria a encontrar o marido, houve comida e bebida à discrição, oferecida a todos, objectos de luxo distribuídos ao povo (as colchas e panos ricos que decoravam as janelas e varandas). Os prémios dos vencedores dos torneios consistiam muitas vezes em valiosos objectos de ouro e prata, ou mesmo pedras preciosas ${ }^{25}$.

As festas do casamento do príncipe Afonso, filho de D. João II, com Isabel, filha mais velha dos Reis Católicos, não foram muito diferentes do caso anterior. Se acreditarmos na narrativa de Garcia de Resende, duraram 15 dias completos, mobilizaram economicamente vastas áreas do Reino e não apenas a de Évora onde se realizaram, e foram pretexto para a importação de numerosos bens de luxo de toda a Europa. D. João II convocou cortes antes, de modo a pedir dinheiro para as financiar, mas em contrapartida as

${ }^{24}$ LISS, Peggy K. - Isabel the Queen ..., cit., p. 67. SUÁREZ FERNÁNDEZ, Luís - Isabel I ..., cit., p. 65. Ao que parece, o acto destinava-se a mostrar que, ao contrário da fama que corria sobre o então rei de Castela (Henrique IV, meio-irmão da noiva), Fernando de Aragão não era impotente. Também, dá-se o caso de os noivos terem casado com uma dispensa papal falsa (VAL VALDIVIESO, Ma Isabel del, La sucesión de Enrique IV. Espacio. Tiempo y Forma, S. III, $H^{a}$ Medieval. 4 (1991) 43-78, especialmente p. 56).

${ }^{25}$ NASCIMENTO, Augusto, BRANCO, Maria João, e ROSA, Maria de Lurdes - Leonor de Portugal, Imperatriz da Alemanha. Diário da Viagem do Embaixador Nicolau Lanckman de Valckenstein. Lisboa: Edições Cosmos, 1992, p. 41-45. 
festas estiveram abertas a todos enquanto duraram, pelo menos no que diz respeito a comida e bebida nas ruas da cidade (excluindo os banquetes na sala da madeira, construída expressamente para as bodas). Escreve Garcia de Resende a propósito destes: "E toda a gente da corte, e da cidade, que estava em pé entre as grades, que era muita, todos comiam do que se tirava das mesas, que era em tanta abundância, que muito mais era o que sobejava, que o que se comia..."26. As festas não se ficaram por Évora, porque os príncipes, quando mais tarde se dirigiram a Santarém iam sendo recebidos nas cidades e vilas com festejos, até que o príncipe morreu de acidente no verão de 1491.

Para meados do século XVI as coisas já tinham mudado a ponto de, no casamento de Joana de Áustria com o príncipe D. João, haver oficiais encarregues de enxotar a multidão com bengalas de cana enquanto a princesa percorria o trajecto entre o cais e o paço à sua chegada - isto não existe para a segunda metade do século $\mathrm{XV}^{27}$. É mais um sintoma de que as formas de poder presencial directo que tinham caracterizado as monarquias de finais da Idade Média se iam esbatendo face a formas mediatizadas de representação.

\section{Vidas privadas ou públicas?}

Como vimos, o enxoval era uma das poucas componentes do dote da noiva que lhe pertencia por direito, e seria naturalmente constituído pelos bens que acompanhavam a vida pública e privada das princesas ou rainhas. Roupas, de corpo ou cama, objectos de uso pessoal, coisas de mesa ou cozinha, e mobiliário litúrgico preenchiam espaços eminentemente domésticos. Eram listas de objectos, elaboradas à margem do contrato nupcial, e que não faziam parte dele: como vimos, apenas os objectos de ouro e prata, e as pedras preciosas podiam integrar as listas de jóias.

Conhecemos os enxovais sobretudo através de inventários, mas constituem uma fonte relativamente rara. Qualquer inventário, e não apenas os de jóias ou enxovais que nos ocupam neste caso concreto, coloca problemas de

\footnotetext{
${ }^{26}$ RESENDE, Garcia de - Crónica de D. João II..., cit., p. 176.

${ }^{27}$ IAN/TT, Manuscritos de S. Vicente, livro 2, fls. 13 e seguintes.
} 
tratamento de variada ordem, alguns deles insolúveis. Em primeiro lugar, temos a representação textual do objecto através da palavra escrita e nunca o objecto em si mesmo ou a sua imagem pictórica. Essas descrições variam, pelo que se torna quase impossível seguir os objectos de inventário para inventário. Trata-se de um problema importante, se tivermos em conta que uma das abordagens actuais da cultura material é a da vida social dos objectos que inclui o estudo da sua circulação e dos significados que assumem em contextos diferentes, naquilo a que Arjun Appadurai chamou "the politics of value" ${ }^{28}$. Nesse sentido, são preciosas as indicações, por vezes feitas à margem, sobre os anteriores proprietários dos objectos (quem os ofereceu, se existem na família e há quanto tempo, etc..). Em segundo lugar, a maior parte dos objectos daquela época caiu em desuso nos nossos dias, bem como as palavras que os designam. Nem todas se encontram nos dicionários, mesmo aqueles que usamos para palavras arcaicas ${ }^{29}$. Desconhecemos a utilização dada a muitos objectos, quem os usava, e em que contexto. Nesse sentido, o recurso aos objectos expostos em museus e às imagens da pintura da época tem-se revelado fundamental ${ }^{10}$.

Os inventários dos enxovais, eminentemente variáveis, podem constar de jóias (ainda que estas pudessem fazer parte do dote), vestidos do corpo (muitas vezes com componentes de ouro, pérolas e pedraria), paramentos de cama, objectos de câmara, mesa, e capela. Havia também a roupa branca, que podia ser de cama, de mesa, e do corpo (nesta época, como se sabe, a roupa interior era exclusivamente constituída por camisas). Ao contrário das escrituras de contratos de casamento, os inventários dos enxovais não são padronizados. Começam geralmente pelas jóias e objectos mais preciosos, mas não procedem aos mesmos agrupamentos. Podem começar

${ }^{28}$ APPADURAI, Arjun - Introduction: commodities and the politics of value in APPADURAI, Arjun (ed.) - The Social Life of Things. Commodities in cultural perspective. Cambridge: Cambridge University Press, 1986, p. 3-63.

${ }^{29}$ Como por exemplo: BLUTEAU, Rafael - Vocabulário Portuguez e Latino. Coimbra: Oficina de Pascoal da Sylva, 1712-1721. VITERBO, Joaquim - Elucidário das palavras, termos e frases que antigamente se usaram e que hoje regularmente se ignoram. Porto: Civilização, 1983-1984.

${ }^{30}$ DENNIS, Flora - Representing the Domestic Interior in Fifteenth and Sixteenth Century Italy: from the birth of the Virgin to palaces of cheese in AYNSLEY, Jeremy and GRANT, Charlotte (eds) - Imagined Interiors. Representing the Domestic Interior since the Renaissance. London: V\&A, 2006, p. 22-45. 
pelos objectos litúrgicos, mas também relegá-los para o fim; outros seguem a ordem das principais funções domésticas, a que correspondem arquétipos como a cama, a mesa, a cozinha e a capela, etc.. Outros parecem ser feitos apenas à medida que se colocam ou retiram coisas de arcas e cofres. Do século XV para o XVI assistimos a uma diversificação dos objectos contidos nos enxovais, paralelamente a uma complexificação crescente, traduzida no aumento do número de objectos. Em todos eles avulta a importância conferida aos metais preciosos e pedraria, e aos têxteis. Mercê da descoberta do caminho marítimo para a Índia, ao longo do século XVI o mercado dos objectos de luxo foi cada vez mais dominado pelos produtos provenientes do Oriente. Muitos inventários elencam grandes quantidades de tecidos em bruto, ainda por talhar e costurar. As arcas e os cofres assumem nestas listas uma dimensão fundamental: numa época anterior aos armários, às cómodas e até em grande medida às gavetas, era nelas que se guardava o enxoval. Este aspecto reflectia o nomadismo das cortes, para quem a riqueza devia ser eminentemente transportável, e ainda, passível de ser transformada em dinheiro. Para termos uma ideia, nos meados do século XV, o enxoval de D. Beatriz em 1445 (a quem chamaremos Brites para a distinguir da neta do mesmo nome), duquesa de Beja e mãe de D. Manuel I, incluía 34 arcas e cofres diversos; o da neta Beatriz, em 1521, incluirá 54. O primeiro destes inventários, por exemplo, menciona os objectos destinados às donzelas ${ }^{31}$. Nas listas posteriores, desaparece a menção a estas últimas, mas continuam a incluir-se muitos objectos do mesmo tipo, o que leva a pensar que se destinam às damas da princesa.

No que toca à emergência da vida privada, dificilmente se pode verificar se existia uma tendência no sentido de uma maior segregação do quotidiano das princesas no interior dos palácios. Em primeiro lugar, devemos entender os aposentos das princesas como espaços domésticos eminentemente femininos, praticamente vedados aos homens.

No caso dos casamentos que vimos analisando, como vimos, havia muito pouco de privado. O contrato representava uma aliança entre reis, o dinheiro do dote podia ser gasto pelo marido, o tempo da corte era abundantemente preenchido com cerimónias e rituais públicos, em espaços tão diversificados

${ }^{31}$ SOUSA, D. António Caetano de - Provas da História ..., cit., tomo I, livro III, 289-295. 
como a capela, a sala de audiências, a sala das refeições. A câmara podia ser de facto o mais privado destes espaços, embora não necessariamente um lugar propenso ao isolamento solitário. As princesas viviam constantemente acompanhadas pelas suas damas e criadas. Foi D. Catarina que aconselhou à filha Maria, noiva do futuro Filipe II, o seguinte: "Por quão bom costume é as mulheres não estarem sós nem só com uma mulher, antes sempre acompanhadas de muitas e as do vosso estado [...] Quando vosso marido não dormir em vossa casa, sempre em vossa câmara dormirão quatro ou cinco mulheres ${ }^{\prime 32}$. Em qualquer dos casos as entradas nos aposentos das princesas eram controladas por porteiros, cujas maças aparecem nos inventários. Mas não deixa de ser curioso que o excerto da carta de D. Catarina aluda veladamente ao perigo de homossexualidade feminina.

\section{Os enxovais: identidade, estatuto e riqueza}

Num contexto em que o casamento significava uma expatriação para as princesas, o papel do enxoval como uma materialização da memória do seu passado nas cortes de origem assumia um significado especial. É certo que outros dispositivos pretendiam criar um pequeno enclave onde a princesa recriasse o ambiente original: as damas que a acompanhavam eram portuguesas, assim como alguns dos homens que desempenhavam funções na sua "casa", que deve ser colocado a par de outros aspectos que teriam a mesma finalidade, como por exemplo o uso da língua de origem, ou a intensa correspondência com a corte natal, etc... ${ }^{33}$

O enxoval inseria-se nesse contexto de construção de um ambiente familiar que conservasse a identidade da noiva e amenizasse as ausências de lugares e pessoas. Era este que personalizaria os seus aposentos e neste contexto assumiam particular importância os objectos consagrados

${ }^{32}$ Relações de Pero de Alcáçova..., cit., p. 307 (sublinhados meus).

${ }^{33}$ Sá, Isabel dos Guimarães - Cousin Marriage and Well-Being among the Portuguese Royal Family during the $15^{\text {th }}$ and $16^{\text {th }}$ Centuries, in Margarida Durães, Antoinette-Fauve-Chamoux, Llorenç Ferrer \& Jan Kok (eds.) - The Transmission of Well-Being. Gendered Marriage Strategies and Inheritance Systems in Europe $\left(17^{\text {th }}-20^{\text {th }}\right.$ Centuries. Bern: Peter Lang, 2009, p. 112-113. 
às devoções quotidianas. O necessário para equipar uma capela estava já incluído no enxoval de D. Brites duquesa de Beja em 1445, bem como as vestes litúrgicas dos oficiantes. Os livros incluídos nos enxovais eram invariavelmente religiosos: missais, breviários, livros de horas, santorais, etc. A maior parte deles fazia parte da secção das jóias, uma vez que eram encadernados a ouro e prata, e por vezes incluíam imagens pintadas a ouro.

Os enxovais dão-nos algumas indicações sobre o processo de privatização. Por exemplo, quando partiu para Sabóia, em 1521, a infanta D. Beatriz levava um luxuosíssimo e abundante enxoval, talvez mais rico que o da sua sobrinha Maria em 1543, mas as peças litúrgicas nele incluídas destinavam-se apenas à sua capela. Em contrapartida, Maria duplicava muitos desses objectos, com a indicação de que alguns deles seriam do seu oratório e outros da capela. Ou seja, disporia de um espaço privado de devoção, onde podia rezar longe dos olhares da corte; em contrapartida, a capela era por excelência um espaço de representação, onde se expunha aos olhares do príncipe seu marido, que assistia à missa na tribuna defronte. Várias cartas nos dão conta do embaraço causado por alguns incidentes com a princesa e a sua corte à vista de todos, e em particular do príncipe Filipe ${ }^{34}$.

$\mathrm{O}$ dote de Beatriz difere também do de Maria num ponto fundamental. Ainda não existia nele uma separação nítida entre o seu enxoval e os objectos de valor, enquanto o que se conhece do de Maria é justamente uma lista destes últimos. Ou seja, o dote de Beatriz elenca coisas menos vendáveis como a roupa e paramentos de cama, e os instrumentos de ferro e cobre da cozinha ${ }^{35}$. Em contrapartida no rol respeitante à infanta D. Maria temos apenas os objectos de prata, ouro e as jóias do corpo, por esta ordem. Não que esta lista não incluísse inúmeros objectos indispensáveis ao bem-estar físico e espiritual da princesa. Uma poma de prata para aquecer as mãos, bacias de prata diferentes consoante a parte do corpo que se destinavam a lavar (pés, mãos, cabeça), uma bacia de barbear, armações de abanos (leques), etc. Alguns historiadores tem falado justamente das tecnologias do corpo e da importância crescente de que os objectos relacionados com a saúde e bem-estar físico ocupam nos espaços domésticos a partir do século

\footnotetext{
${ }^{34}$ In Gavetas ..., cit., vol. IV, p. 155-160 [1544.04.29].

${ }^{35}$ SOUSA, D. António Caetano de - Provas da História ..., cit., vol. II, parte II, p. 27-81.
} 
$\mathrm{XVI}^{36}$. Por outro lado, existem formas de consumo marcadas pelo género de que os enxovais são um exemplo flagrante: a esmagadora maioria dos objectos listados está relacionada com um quotidiano doméstico, vivido sobretudo em espaços fechados ${ }^{37}$. Ao contrário dos homens, que viajavam com maior frequência e passavam longas temporadas ao ar livre, quer na caça ou em campanha militar, às mulheres estava reservado um tipo de vida mais sedentarizado, embora não totalmente, uma vez que também se deslocavam de palácio para palácio.

Todos os objectos referidos no rol das jóias da princesa Maria, foram, no cumprimento estrito do contrato de casamento, avaliados por agentes de ambas as partes contraentes, e o seu valor descontado no dote a pagar ${ }^{38}$. Portanto, parte do dote de Maria era enxoval e parte do enxoval fazia parte do dote, o que podia criar uma situação complicada. O que aconteceria se Filipe quisesse penhorar ou fundir a poma de prata? A imperatriz Isabel, por exemplo, preferiu concentrar os seus investimentos de carácter sumptuário nas peças do seu guarda-roupa, uma vez que as jóias do seu dote serviam para pagar as dívidas de Carlos V. De resto, entre as poucas "relíquias" da sua realeza que deixou figuram uns paramentos feitos com vestidos seus que doou ao mosteiro de Guadalupe ${ }^{39}$.

Mas é cedo para falar de vida privada relativamente a estas princesas. A vida da infanta D. Maria, enquanto foi casada com o príncipe de Castela (futuro Filipe II) esteve debaixo do escrutínio constante dos cortesãos portugueses que estavam encarregues de dar conta dos mais ínfimos detalhes da sua vida. Na maior parte das vezes, as cartas revelam que as coisas corriam francamente mal para a princesa. Ao contrário de outras raparigas que encontravam a atitude e o comportamento certos para lidar com a vida de corte, a princesa não conseguiu fazê-lo. Pais e criados de sua

${ }^{36}$ CAVALLO, Sandra - Health, beauty and hygiene, in AJMAR-WOLHEIM, Marta e DENNIS, Flora (eds) - At Home in Renaissance Italy. London: V\&A, 2006, pp. 174-187.

${ }^{37}$ Cf. BROWN, Patricia Fortini - Private Lives in Renaissance Venice. New Haven: Yale University Press, 2004, p. 91-121.

${ }^{38}$ SOUSA, D. António Caetano de - Provas da História..., cit., vol. III, parte I, p. 211-245.

${ }^{39}$ SEBASTIÁN LOZANO, Jorge - Choices and Consequences: The Construction of Isabel de Portugal's Image in EARENFIGHT, Theresa, (ed.) - Queenship and Political Power in Medieval and Early Modern Spain. London: Ashgate, 2005, p. 157. 
casa trocavam cartas apreensivas; o príncipe Filipe mantinha-se à distância, até que, como se sabe, a princesa morreu de parto, dando à luz o príncipe D. Carlos, uma figura trágica a ponto de se transformar numa personagem de ópera (Don Carlo de Verdi). Em comparação com a imperatriz Isabel, que tinha casado com Carlos V cerca de vinte anos antes, a vida da princesa de Castela parece ter sido objecto de uma apertada vigilância por parte dos cortesãos portugueses que a acompanharam, constantemente em contacto com os seus pais em Portugal. Tudo aponta, de facto, para um crescente escrutínio da vida das princesas, potenciado pelo aumento de cortesãos com funções de vigilância e pelo consequente acréscimo de correspondência escrita com a corte de origem, ou outras cortes europeias.

É nítido nos enxovais analisados algumas pequenas novidades que anunciam os novos tempos: espelhos, leques, guardanapos, e os garfos e colheres. Os primeiros eram conhecidos na Idade Média, embora fossem feitos de metal e não e vidro, como na época moderna; os segundos foram seguramente uma inovação proporcionada pela importação de objectos orientais, sobretudo na sua versão individual; guardanapos e garfos fizeram parte das inovações propiciadas pelas novas regras de etiqueta à mesa. No que respeita a móveis, não será acertado tentar analisar a sua evolução através deste tipo de fonte, por duas ordens de razões: em primeiro lugar, estava-se ainda muito longe da diversidade de mobiliário que caracterizaria séculos posteriores; a maior parte das peças tinham de acompanhar ainda a corte nas suas deslocações e eram eminentemente portáteis. Era também vulgar, dentro do mesmo palácio, montarem-se e desmontarem-se mesas (as salas onde se comia tinham um carácter volante dentro dos paços), deslocarem-se bancos e cadeiras. Por outro lado, as peças mais volumosas, como as camas, embora as houvesse desmontáveis e de "campanha", tendiam a ser site specific, isto é, construíam-se para um sítio preciso e eram dificilmente transportáveis. Ainda assim, o número de cadeiras aumentou bastante entre o enxoval de D. Brites duquesa de Beja e o da sua neta Beatriz. Note-se também que existia a tradição na corte portuguesa de as mulheres se sentarem num estrado e de o uso da cadeira ser apanágio do género masculino ${ }^{40}$.

${ }^{40}$ Com a excepção provável de Catarina de Áustria, que se sentava ao lado de D. João III nas ocasiões oficiais. Cf. Jordan, Annemarie - The Development of Catherine ..., cit., p. 67. 
Mesmo quando as havia em cima dos estrados, era aos homens que cabia geralmente usá-las, ou às mulheres que desempenhavam funções masculinas, como por exemplo quando D. Catarina, viúva do rei, desempenhou as funções de regente do reino na menoridade do neto Sebastião. Os têxteis que decoravam paredes, os couros gravados (guadamecis) também usados na decoração de paredes e móveis, a roupa de cama, que tinha o carácter de uma verdadeira paramentaria, as toalhas de corpo e mesa, os guardanapos, eram em contrapartida ponto de honra nos enxovais das princesas, como o foram sempre, à sua escala relativa, nos das camponesas ou nas noivas dos extractos urbanos.

\section{Conclusões}

As coisas que as noivas levavam no seu enxoval eram uma das formas através das quais as princesas mantinham a sua identidade e conservavam a memória das suas origens nas cortes estrangeiras onde iriam residir. Deslocadas da sua terra de origem, a que só voltavam em caso de viuvez, tinham nos objectos que as acompanhavam para o casamento uma âncora fundamental, capaz de criar um ambiente próximo do de casa. Quanto aos espaços e aos objectos que as acompanhavam, é certo que se foram diversificando e aumentando de número. Em vez de ter só uma capela passaram a ter também um oratório, o numero de objectos foi cada vez maior, os seus materiais cada vez mais conspícuos. O aparato com que saíam dos palácios traduziu-se no aparecimento de sofisticadas carruagens, sendo que tomou cada vez mais incremento o oficialato das suas casas encarregue das cavalariças e veículos de transporte ${ }^{41}$. Como vimos, na década de quarenta do século XVI, dote e enxoval eram acompanhados de processos eminentemente burocráticos: a princesa das Astúrias, Maria de Portugal, filha de D. João III e D. Catarina, viu os seus objectos preciosos avaliados por representantes das coroas espanhola e portuguesa, para além

${ }^{41}$ LABRADOR, Félix - Las caballerizas de las reinas en la monarquía de los Austria: cambios institucionales y evolución de las etiquetas, 1559-1611. Studia Historica. Historia Moderna. 28 (2006) 87-140. 
de ser necessária escrituração para usar as peças que integravam o respectivo inventário. Nada nos permite falar de um processo de privatização que respeitasse o foro íntimo destas princesas e rainhas: pelo menos ao longo do século XVI, a sua vida continuava a pertencer, senão ao povo (as cortes retraíam-se cada vez mais sobre si mesmas), pelos menos aos cortesãos que as acompanhavam em todos os momentos do dia. Havia apenas diferentes graus de exposição pública, entre a toilette diária, assistir à missa ou participar nos rituais políticos da corte.

Grande parte dos objectos que figuravam nos enxovais tinham o valor de semióforos para seguirmos o conceito de K. Pomian. Para este autor correspondem a objectos que uma dada sociedade reconhece como portadores de significados, e que, de forma parcial ou exclusiva, se destinam a ser olhados, ainda que possam conservar a sua função utilitária. Partilham com a linguagem escrita a capacidade de estabelecer a ligação entre o ausente e o presente, o visível e o invisível ${ }^{42}$. Muitos objectos que faziam parte dos enxovais, pelos metais e pedras preciosas usados no seu fabrico, eram em si mesmo semióforos, testemunhando a riqueza e a grandeza das suas possuidoras e das suas cortes de origem ${ }^{43}$. No caso das princesas, tinham ainda de estabelecer a ligação entre o presente e o passado, e funcionar como marcas de uma identidade, que, embora perdida, tinha de ser conservada.

E é também sintomático que as manobras da alta política e os grandes negócios efectuados através dos contratos matrimoniais acabassem por ter o seu desfecho nos corpos destas mulheres. Era sobre a sua capacidade reprodutiva que todo o sistema repousava; por isso, os "vestidos e atavios de pessoa, câmara e casa" giravam em torno do bem estar físico das princesas ou rainha.

${ }^{42}$ POMIAN, K. - Histoire culturelle, histoire des sémiophores in POMIAN, K. - Sur l'histoire. Paris: Gallimard, 1999, p. 205.

${ }^{43}$ Sobre a natureza de matérias significantes dos metais e substâncias raras, cf. POMIAN, K. - Des saintes reliques à l'art moderne. Venise-Chicago XIIIe-XXe siècle. Paris: Gallimard, 2003, p. 160. 